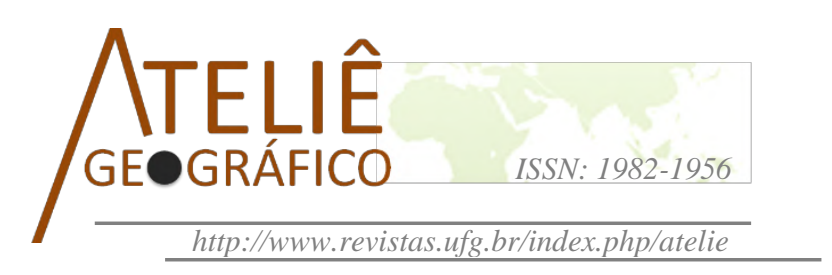

\title{
Geografia, paisagem, literatura e geopatrimônio nas obras de Guimarães Rosa
}

\author{
Geography, landscape, literature and geoheritage in the \\ works of Guimarães Rosa
Geografía, paisaje, literatura y geopatrimonio en las obras de Guimarães Rosa

\author{
Vania Kele Evangelista P. \\ Centro Federal de Educação Tecnológica de Minas Gerais \\ vaniakele@yahoo.com.br
}

Luiz Eduardo Panisset Travassos

Pontifícia Universidade Católica de Minas Gerais

luizepanisset@gmail.com

\begin{abstract}
Resumo
A paisagem é um tema muito abordado na geografia desde os tempos mais antigos. Contudo, seu estudo não se limitou a apenas a essa ciência. Despertou interesse em vários outros campos da ciência e em diferentes profissionais como o escritor Guimarães Rosa que teve um olhar especial para as paisagens de Minas Gerais. É nesse cenário com suas serras, chapadas, rios e veredas que o autor criou seus personagens expondo a vida de um povo sofrido e encantador. Diante de tamanha beleza e riqueza de detalhes dos elementos do patrimônio natural descritos pelo autor no sertão mineiro torna-se necessário elencar alguns locais de destaque nas suas obras para que as pessoas, ao visitarem os locais, tenham acesso a informações de cunho turístico, científico e educativo. Nesse viés, a partir da leitura das obras rosianas e dos Marcos Territoriais do Circuito Guimarães Rosa (CGR) surge a proposta de identificação do geopatrimônio e a criação do Roteiro Geoturístico Sertões de Minas Gerais (SMG) que visa contribuir para o desenvolvimento sustentável regional por meio de ações que priorizem as comunidades locais e os elementos físicos descritos pelo escritor.

Palavras-chave: Geografia; Paisagens; Geopatrimônio; Guimarães Rosa.

Abstract

The landscape is a subject much studied in geography since its beginnings. However, its study was not limited to just this science. It aroused interest in several other fields of study and in different professionals like the writer Guimarães Rosa who had a unique look for the landscapes of Minas Gerais. It is in this scenery with hills, plateaus,
\end{abstract}


rivers and marshlands that the author created his characters exposing the life of suffering and charming people. Faced with such beauty and richness details of the elements of natural heritage described by the author in the Sertão of Minas Gerais, it is necessary to list some prominent places in his works so that people, when visiting the sites, have access to information of a tourist, scientific and educational point of view. Thus, it is proposed the identification of the geoheritage and the creation of the Geotourism Route Sertões de Minas Gerais (SMG), which aims to contribute to the regional sustainable development based on the author's novels as well as the Territorial Landmarks of the Guimarães Rosa's Circuit (CGR) actions that prioritize local communities and the physical elements described by the writer.

Keywords: Geography; Landscape; Geoheritage; Guimarães Rosa.

\begin{abstract}
Resumen
El paisaje es un tema muy abordado en la geografía desde los tiempos más antiguos. Sin embargo, su estudio no se limitó a esta ciencia. Despertó interés en varios otros campos de científicos y en diferentes profesionales como el escritor Guimarães Rosa que tuvo un enfoque especial para los paisajes de Minas Gerais. Es en ese escenario con sus sierras, chapadas, ríos y veredas que el autor creó sus personajes exponiendo la vida de un pueblo sufrido y encantador. Ante la magnífica belleza y riqueza de detalles de los elementos del patrimonio natural descritos por Rosa en el interior de Minas Gerais se hace necesario enumerar algunos lugares destacados en sus obras para que las personas, al visitar los locales, tengan acceso a informaciones de carácter turístico, científico y educativo. En este sentido, a partir de la lectura de las obras rosianas y de los Marcos Territoriales del Circuito Guimarães Rosa (CGR) surge la propuesta de identificación del geopatrimonio y la creación del Itinerario Geoturístico Sertões de Minas Gerais (SMG) que pretende contribuir al desarrollo sostenible regional por medio de acciones que prioricen las comunidades locales y los elementos físicos descritos por el escritor.
\end{abstract}

Palabras clave: Geografía; paisajes; Geopatrimonio; Guimarães Rosa.

\title{
Introdução
}

A busca por novas abordagens tem permeado a Geografia ao longo de sua evolução, contudo alguns temas quase sempre estiveram presentes. Neste caso, o estudo das paisagens que, na vertente cultural, recebeu destaque associado as questões de interação entre homem e meio, resgatando a abordagem presente na geografia tradicional, bem como o elo existente entre o lugar e o espaço, ambos temas clássicos da Geografia (CLAVAL, 2002). Tal temática reforça a proximidade existente entre as demais ciências e outras áreas do conhecimento, dentre elas, a literatura. Por esse motivo, esta pesquisa destaca as obras de Guimarães Rosa e de que forma é possível aliar sua leitura com o espaço geográfico nos sertões de Minas Gerais.

Ferreira (2007) afirma que a literatura pode ser considerada como um elo que liga os diferentes tipos de realidade, incentivando o diálogo entre diversas áreas do conhecimento. Por esse motivo, a literatura se torna um recurso transdisciplinar, pois engloba diversas disciplinas como a geografia, a história, a biologia, a língua portuguesa e as artes, por exemplo. Percebe-se, portanto, que é de grande importância a articulação entre a literatura e a geografia, principalmente quando é utilizada nas questões que envolvem a relação entre o homem e o meio natural, estreitando as relações entre o espaço geográfico e os leitores (COLFERAI; GOMES, 2009). 
Levando em conta a literatura rosiana, que busca retratar e divulgar o sertão mineiro para o mundo, Evangelista (2018) afirma que a descrição rosiana não é marcada pela segregação, mas sim, pela multiplicidade de detalhes dos cenários e fatos populares. Dessa forma, observa-se que suas obras, além de apreensão de distintos aspectos históricos-geográficos, auxiliam o leitor na compreensão do sertão mineiro em parte do século XX (EVANGELISTA, 2018).

Ao analisar as obras rosianas, nota-se a exposição de muitos elementos naturais importantes para o desenvolvimento regional, bem como para a manutenção da vida no Planeta. Vale destacar que essa preocupação com os elementos do meio físico teve seu ápice na segunda metade do século XX, principalmente na década de 1970, com grandes acontecimentos como a revolução ambiental e a Convenção para a Proteção do Patrimônio Mundial, Cultural e Natural (1972), ocorrida em Paris (BUREK; PROSSER, 2008). Tais ações desencadearam várias inciativas que colocaram em frequente pauta o patrimônio natural, a geodiversidade, o geopatrimônio, o geoturismo e a geoconservação, especificamente a partir da década de 1990. Para Kozlowski (2004), tais temas aproximaram os geocientistas das questões ligadas ao ordenamento territorial, à conservação da natureza e ao desenvolvimento sustentável das comunidades rurais.

Diante desse quadro de conservação da natureza surgem algumas propostas voltadas aos elementos do meio natural que visam a conservação e valorização das características geológicas, geomorfológicas, seus processos e sítios (BRILHA, 2005). No caso desta pesquisa, os autores buscaram identificar os elementos notáveis do geopatrimônio do sertão mineiro rosiano, valorizando-os sobre a ótica geoturística e propondo o Roteiro Geoturístico Sertões de Minas Gerais (SMG) que visa a promoção da atividade turística e do desenvolvimento regional sustentável no cenário descrito por Guimarães Rosa nos livros Corpo de Baile (1956), Grande Sertão: veredas (1956), Primeiras Estórias (1962), Ave Palavra (1970-obra póstuma), entre outros trabalhos.

Criado a partir dos aspectos geográficos, literários, culturais e do limite geográfico do Circuito Guimarães Rosa, o Roteiro Geoturístico SMG dispõe de uma área aproximada de 2.332,050 há, conforme Figura 01. 


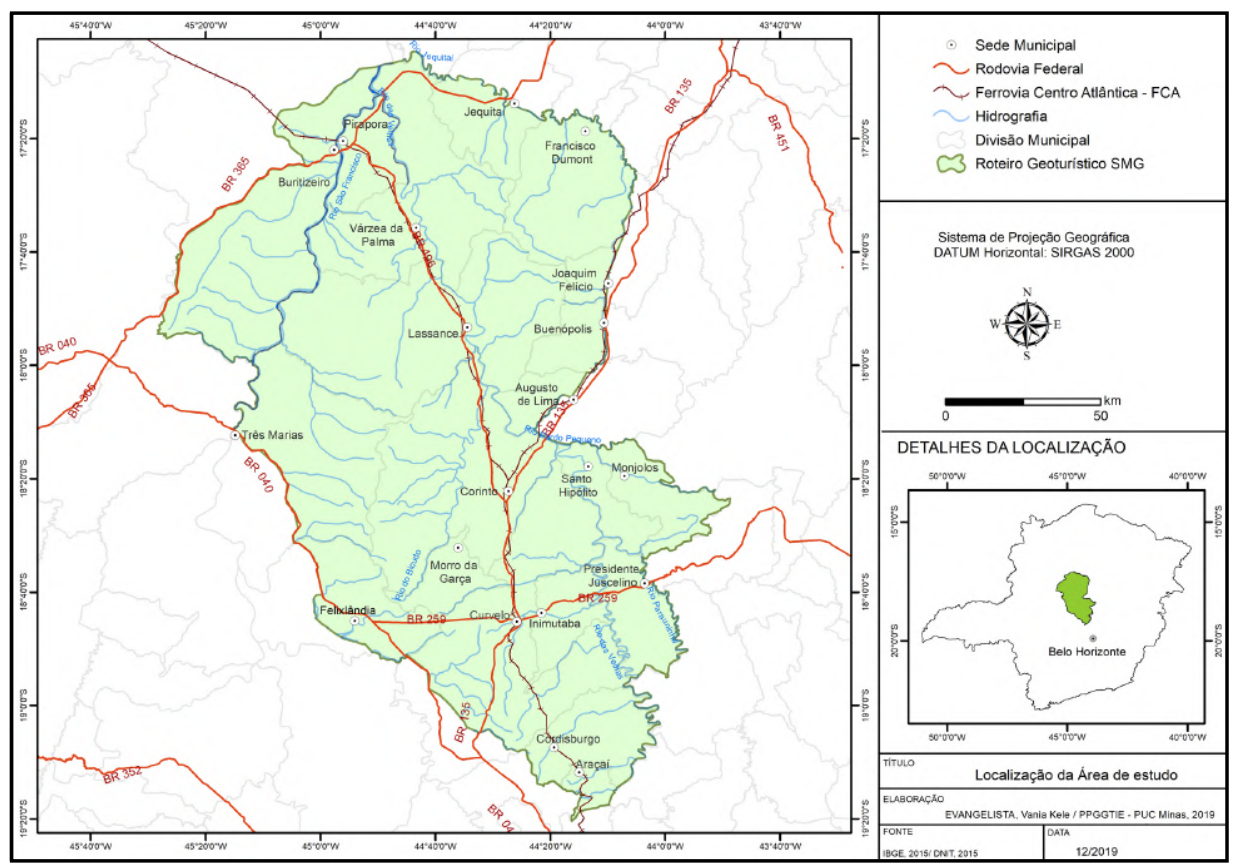

Figura 01: Mapa de localização do Roteiro Geoturístico Sertões de Minas Gerais.

\section{Geografia, paisagem e literatura: uma aproximação}

O campo das ciências está sempre em busca de novos desafios, ao mesmo tempo que retoma conceitos e temas clássicos. Com a geografia não é diferente ao resgatar os estudos da paisagem na corrente humanista e cultural em uma perspectiva antropocêntrica e holística, valorizando aspectos geográficos como o espaço e o lugar, por exemplo (FONT, 1985). Para Tuan (2013), ao apreciar tal abordagem os geógrafos adeptos dessa corrente passam a humanizar os espaços, os lugares e a paisagem no sentido de realmente entendê-los sob a ótica humana com sentidos e emoções.

De acordo com Amorim Filho (2008), essa abordagem mais integradora da geografia que envolve os seres humanos, o meio ambiente e a interação entre as esferas física e humana ganhou força no final do século XIX e início do século XX. Vale ressaltar que essa relação entre o ser humano e o meio é consolidada pela localização dos fatos no espaço geográfico real com a interação antrópica (SEAMON; LUNDBERG, 2017). Tal percepção de lugar atrelada aos elementos humanos era algo questionado por alguns geógrafos, ou seja, era necessário compreender suas relações não apenas pela ciência, mas também, pela emoção. Diante dessa demanda cresce, na geografia uma abordagem voltada a descrição do "mundo cotidiano da experiência imediata do homem, incluindo suas ações, lembranças, fantasias e percepções" (RELPH, 1970, p. 193). 
Para Amorim Filho (2008) nessa percepção geográfica a paisagem é retomada, sobretudo, ao ser descrita como uma região integradora e como uma componente principal que associa elementos físicos e humanos. Assim, o termo paisagem, que tem suas origens ligadas a arte e a pintura, não era inicialmente atrelado a geografia. Contudo, de acordo com Luchiari (2001), a aproximação ocorreu quando o sítio (lugar) foi elevado à categoria de paisagem, favorecendo novas análises que acompanharam as distintas fases de evolução do pensamento geográfico.

Claval (2001) destaca a importância das paisagens no contexto geográfico, principalmente no campo da geografia cultural, ao apresentar três fases de contribuições. A primeira está relacionada a análise da morfologia das paisagens ao encará-la como resultante da ação entre a esfera natural e cultural, como propôs Sauer (1925); a segunda, voltada para uma nova paisagem no período de pós-guerras, busca certa uniformização dos ambientes com a mecanização, porém esquecendo-se das interações mais complexas. A terceira fase, ocorrida na década de 1970, surge quando a paisagem passa a ser associada como um resultado da interação entre natureza e sociedade, expressando a cultura daquele povo.

Ao ganhar força dentro da corrente humanista e cultural, foi na terceira fase que a paisagem passou a ser analisada com um olhar especial pelos geógrafos ao perceberem as cores, perfumes, formas e sons no mundo. Essa visão ocorre em virtude da associação da paisagem real (resultado da combinação dos meios físico, biológico e antrópico) que, interligados, formam um conjunto único, inseparável e em plena evolução (BERTRAND, 1968). Para Evangelista (2018), a paisagem vai muito além do horizonte visualizado e das esferas natural e cultural; ela está presente na interpretação de cada indivíduo ao manter qualquer contato com o mundo em suas diferentes escalas. Ou seja, está presente com a leitura de um texto, ao escutar uma canção ou simplesmente ao abrir a janela de casa.

Para Marandola Jr. e Gratão (2010) essa aproximação entre a geografia e a paisagem pode ser facilitada pela literatura uma vez que ela menciona a realidade do espaço geográfico por meio da descrição dos fatos de suas obras. As obras literárias, carregadas de emoções, trazem consigo fatos do cotidiano de um povo, bem como as características de um período histórico, político e econômico. Ferré (1954) destaca que o interesse pela literatura na geografia vem desde as conhecidas obras de Homero, até os geógrafos Humboldt, Vidal de La Blache, Jean Brunhes e Pierre Defftaines, dentre outros.

O interesse pela literatura também foi impulsionado no século XIX quando as sociedades geográficas de países europeus promoveram e patrocinaram expedições e viagens de exploração, a partir de 1821. Tais viagens acabaram contribuindo para o conhecimento de lugares nunca visitados antes (AMORIM FILHO, 2008; CUNHA, 2011). Para Travassos e Amorim Filho (2016), no mundo medieval, os relatos foram indispensáveis para a conquista de novos territórios e ações militares. Além disso, ampliaram o imaginário geográfico e cartográfico ao buscar, por meio da literatura, mais conhecimento sobre diferentes lugares, regiões, paisagens e o próprio comportamento humano. 
De acordo com Lévy (2006) e Collot (2015), alguns autores ampliaram seus estudos por meio da literatura com as obras de Bukowski (1973), Simon (1981; 2009), Porteous (1990) e Moretti (2000). Aproximação semelhante aconteceu no Brasil por meio de obras de arte, romances, gravuras, pinturas antigas e demais ações ligadas a literatura como o trabalho de Ferreira (1990) e sua percepção geográfica da paisagem do "Grande Sertão: veredas", de João Guimarães Rosa (PINHEIRO NETO, 2012).

Nesse contexto, muitas demandas sugiram e a união entre a geografia, a paisagem e a literatura passou a ser foco de diversos eventos acadêmicos. Tais ações refletem a importância dessa associação que muito tem a contribuir na potencialização dos estudos geográficos e, ao mesmo tempo, favorecer o despertar do interesse turístico nos leitores como já vem ocorrendo na região do Lake District (Reino Unido) retratado por William Wordsworth, na Riviera Francesa, de Scott Fitzgeralde, os Alpes franceses de Hermann Hesse e o Velho Oeste norte americano de Karl May, dentre outros (LÉVY, 2002).

No Brasil destacam-se as obras de Érico Veríssimo (Rio Grande do Sul), José de Alencar (Ceará), Jorge Amado (Bahia), João Cabral de Melo Neto, Ariano Suassuna e, José de Alencar (Nordeste) e Guimarães Rosa (sertão mineiro). A importância das obras literárias ultrapassa o campo da leitura ao despertarem o leitor para os campos da literatura, do turismo, do patrimônio natural e de sua conservação.

\section{Geodiversidade, geopatrimônio, geoconservação e geoturismo}

A segunda metade do século $\mathrm{XX}$ foi muito importante para o desenvolvimento da corrente da geografia humanista e cultural e sua percepção do espaço vivido. Além disso, foi neste período que ocorreu o fortalecimento de movimentos em prol da conservação da natureza que se preocupavam com o intenso processo de industrialização aliado a reconstrução do pós-guerra. Com isso, destacam-se algumas iniciativas isoladas em prol da vertente abiótica do patrimônio natural, ou seja, a geodiversidade ou o substrato responsável pela existência da vida na Terra (GRAY, 2004). O termo, até então pouco mencionado, foi utilizado na década de 1940 pelo geógrafo argentino Frederico Alberto Daus no campo da geografia cultural com o intuito de identificar a diversidade paisagística associada a intervenção humana (CAÑADAS; FLAÑO, 2007).

De acordo com Burek e Prosser (2008), a temática encontrava-se em meio as preocupações da nova estrutura da sociedade, culminando com a Convenção para a Proteção do Patrimônio Mundial, Cultural e Natural (1972), em Paris. Na Convenção foram discutidas ações que visavam atribuir valor de conservação ao patrimônio mundial por meio de uma estratégia global voltada para a diversidade natural e cultural de seus elementos (UNESCO, 2018). Em seguida, ocorreu uma ampliação desta abordagem, incorporando as esferas natural e cultural no que se conhece hoje como patrimônio mundial misto (IPHAN, 2008).

A proposta da UNESCO de valorização do patrimônio natural que está associada a manutenção da vida na superfície terrestre ganhou mais adeptos no início da década de 1990. Desde então, foram realizados vários eventos como o Simpósio sobre a Proteção 
do Patrimônio Geológico (em Digne-Les-Bains, França), em 1991, com a aprovação da Declaração Internacional dos Direitos à Memória da Terra (RUCHKYS, 2007). Na sequência, em 1992, aconteceu a Convenção sobre a Biodiversidade na Terra (Eco-92), no Rio de Janeiro, com o objetivo de promover o desenvolvimento sustentável e a disseminação de medidas protecionistas concomitantes à gestão e ao ordenamento territorial da biodiversidade (CARCAVILLA; DURÁN; LÓPEZ-MARTÍNEZ, 2008).

Para Gray (2004), é nesse contexto que o termo geodiversidade é proposto por alguns pesquisadores durante a Conferência de Malvern sobre a Conservação Geológica e Paisagística (1993), ocorrida no Reino Unido. Nos anos seguintes a geodiversidade foi incorporada a inventários, a estudos sobre elementos geológicos e geomorfológicos, livros e artigos, sobretudo aqueles ligados a história da Terra. Diante da relevância da temática, Sharples $(1995 ; 2002)$ a define a geodiversidade como sendo a diversidade de sistemas e processos geológicos, geomorfológicos e pedológicos atuando em conjunto. Pautado nesses princípios, Gray (2004, p. 8) entende a geodiversidade como a variedade natural de aspectos geológicos (e.g. minerais, rochas e fósseis), geomorfológicos (e.g. formas de relevo, processos) e do solo, incluindo suas correlações, propriedades, interpretações e sistemas. Contudo, o autor acrescentou novas categorias a proposta inicial de Sharples (1995; 2002), atribuindo valores à geodiversidade com o intuito de reforçar a sua conservação (GRAY, 2013).

A geodiversidade se difundiu e, da mesma forma que a biodiversidade, passou a ser incorporada no Brasil. As primeiras atribuições estão relacionadas as práticas de conservação dos elementos do meio físico associados ao planejamento territorial (econômico e político) com o intuito de atender os parâmetros de desenvolvimento sustentável (SILVA et al., 2008). No início do século XXI, ganhou destaque em projetos da Companhia de Pesquisa de Recursos Minerais e Serviço Geológico Brasileiro (CPRM/SGB) sendo definida pela como natureza abiótica formada por distintos ambientes, fenômenos e processos geológicos que formam paisagens e atuam no desenvolvimento da vida na Terra, além ser dotada de valores intrínseco, cultural, estético, econômico, científico, educativo e turístico (CPRM/SGB, 2006).

Simultaneamente à proposta da geodiversidade encontra-se o termo geoheritage, proposto por Wiedenbein (1994), para a conservação de elementos notáveis do meio natural. Componente da geodiversidade, o geopatrimônio (Geoheritage) é formado pelos elementos da natureza abiótica que são dotados de valores intrínsecos, ecológicos e funcionais que devem ser conservados, pois auxiliam na integridade do geossistema (SHAPLES, 2002). Smith-Meyer e Wimbledon (2012) atribuem o geoheritage ao patrimônio geológico e às suas heranças ligadas a geologia e a cultura moderna. Entretanto, surge uma proposta mais integradora que vai além dos elementos abióticos da geodiversidade, ou seja, que comporta os patrimônios geológico, geomorfológico, paleontológico, estratigráfico e mineralógico, entre outros (RODRIGUES; FONSECA, 2008).

Desta forma, o geopatrimônio é parte integrante do patrimônio natural global (Figura 02) que abrange locais de interesse como os sítios, os fósseis, as rochas, os 
minerais e a paisagem que desempenham papel fundamental para se compreender a história da Terra (PROGEO, 2011). Pautados nesse conceito encontram-se os sítios da geodiversidade, ou seja, os locais de interesse in situ que dispõem de formas relevantes e apresentam diferentes valores científico, estético, cultural e turístico. Nesse artigo são identificados como as cavidades naturais subterrâneas, rios, serras, lagoas, chapadas, veredas e outras feições da paisagem cárstica. Já os sítios da geodiversidade ex situ compreendem geoformas dotadas de valor que são importantes recursos para educação, turismo ou identidade cultural de comunidades que estão disponíveis para pesquisa em coleções e museus (BRILHA, 2016).

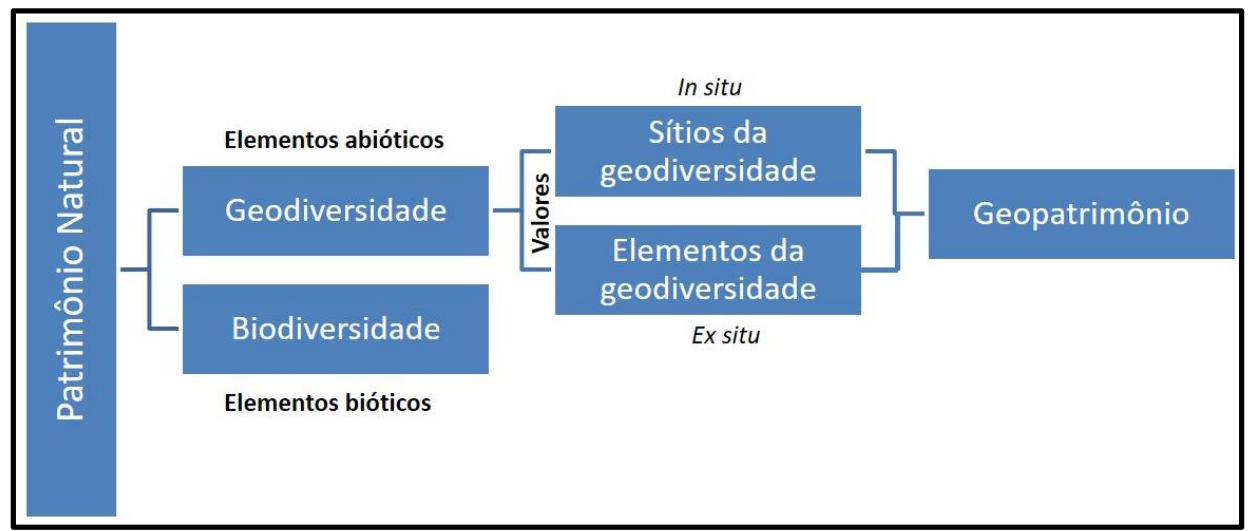

Figura 02: Inter-relação entre os elementos do patrimônio natural e o geopatrimônio. Fonte: Adaptado de BRILHA, 2016, p. 120.

Assim, a geoconservação surge a partir da significativa necessidade de conservar o geopatrimônio, os sítios da geodiversidade e manter a interação dos sistemas terrestres com a promoção do desenvolvimento regional sustentável. A geoconservação passa a ser, então, uma proposta que visa salvaguardar o patrimônio abiótico a fim de forma garantir a sua existência para as outras gerações, ou seja, tentando manter uma relação mais harmônica entre os elementos da geodiversidade, biodiversidade e o homem (BUREK; PROSSER, 2008). Para Erikstad (2008), a geoconservação é efetivada por meio de ações, inventários e da legislação vigente em cada país que direciona esforços para a conservação do patrimônio natural.

A geoconservação, inicialmente atrelada a vertente geológica, foi expandida e definida por Sharples (2002) como a conservação da diversidade natural significativa de origem geológica (formações rochosas), geomorfológica (relevo) e pedológica (solo e processos) que, em equilíbrio, mantêm índices aceitáveis de saúde ambiental no geossistema. Nessa esfera, Brilha (2005) propõe a gestão sustentável do patrimônio geológico como forma de utilizar, bem como de salvaguardar as formas mais relevantes. Tais práticas geoconservacionistas se difundiram e apoiaram-se nos conceitos de 
desenvolvimento regional sustentável, na promoção da identidade territorial e na utilização racional dos elementos da geodiversidade (PEREIRA, 2010).

Desta forma, a geoconservação não é uma ação isolada, mas sim, uma ação integrada e composta por iniciativas que visam promover, valorizar, divulgar e garantir a integridade do geopatrimônio por meio da criação de rotas geoturísticas e painéis interpretativos, por exemplo (LIMA; VARGAS, 2014). Para Tavares et al. (2015), a geoconservação contribui para a produção de conhecimento, bem como amplia as inciativas ligadas a educação, promove o turismo, valoriza os recursos locais e incentiva o desenvolvimento de estratégias de planejamento, sustentabilidade e práticas geoturísticas.

As práticas geoturísticas estão associadas a uma nova forma de turismo que, de acordo com Hose (1995), valoriza o geopatrimônio nacional e proporciona aos visitantes conhecimento e compreensão sobre os aspectos geológicos e geomorfológicos do local (DOWLING; NEWSOME, 2010). Durante alguns anos essa abordagem foi discutida e abordada por Frey (1998), Slomka e Kicinska-Swiderska (2004), Ruchkys (2005; 2007), Joyce (2006), e Nekouiesadry (2009), entre outros. Contudo, existe uma outra proposta do geoturismo ligada à geografia e não apenas à geologia (ALLAN, 2011).

Pautados na esfera dos fundamentos geológicos e geomorfológicos destaca-se a definição de Hose $(2000 ; 2011)$ que entende o geoturismo como a provisão de facilidades interpretativas e serviços para promover o valor e os benefícios sociais de lugares, elementos geológicos e geomorfológicos, com o objetivo de assegurar sua conservação para uso de estudantes, turistas e outras pessoas com interesse recreativo ou de lazer. Para Evangelista (2018), o geoturismo é uma forma diferenciada de apreciar a diversidade natural onde o visitante contempla a beleza cênica e obtém informações sobre o geopatrimônio local e regional.

\section{O geopatrimônio no sertão mineiro de Guimarães Rosa}

O sertão mineiro rosiano é composto por um geopatrimônio único, repleto de belas paisagens naturais e culturais como serras, chapadas, rios e veredas. Tais elementos, ou sítios da geodiversidade (SG), são geoformas dotadas de usos distintos que condicionam a biodiversidade local e a atividade econômica. Destaca-se que é essa paisagem singular, com diversos elementos naturais que se propõe divulgar e proteger sob a ótica geoconservacionista por meio de ações que culminaram com a seleção de 20 sítios da geodiversidade descritos na Tabela 01 . 
Tabela 01. Seleção dos Sítios da Geodiversidade inventariados

\begin{tabular}{|c|c|c|c|c|c|}
\hline ID & Lat & Long & Sítios da Geodiversidade & Município & Obras \\
\hline 1 & $-19,12$ & $-44,35$ & Lapa Nova do Maquiné & Cordisburgo & RM \\
\hline 2 & $-18,64$ & $-44,08$ & Gruta das Abelhas & Presidente Juscelino & GS \\
\hline 3 & $-18,62$ & $-44,41$ & Lapa dos Mosquitos & Curvelo & GS \\
\hline 4 & $-18,57$ & $-44,62$ & Mirante do Morro da Garça & Morro da Garça & RM \\
\hline 5 & $-18,30$ & $-44,23$ & $\begin{array}{l}\text { Rio das Velhas na Ponte Férrea em Santo } \\
\text { Hipólito }\end{array}$ & Santo Hipólito & GS \\
\hline 6 & $-18,32$ & $-44,12$ & Lapa do Rozilho & Monjolos & GS \\
\hline 7 & $-18,30$ & $-44,15$ & Maciço e o rio Pardo Pequeno & Monjolos & GS \\
\hline 8 & $-18,28$ & $-44,04$ & Mirante em Rodeador & Monjolos & GS \\
\hline 9 & $-18,10$ & $-44,54$ & Serra do Bicudo - Beltrão & Corinto & GS \\
\hline 10 & $-17,90$ & $-44,61$ & Gruta da Ponta & Lassance & GS \\
\hline 11 & $-17,75$ & $-44,17$ & Cachoeira do Boqueirão & Joaquim Felício & GS \\
\hline 12 & $-17,70$ & $-44,18$ & Metarenitos da Serra do Cabral & Joaquim Felício & GS \\
\hline 13 & $-17,64$ & $-44,22$ & Lagoa Azul & Francisco Dumont & GS \\
\hline 14 & $-17,28$ & $-44,41$ & Mirante na Serra do Boqueirão & Jequitaí & GS \\
\hline 15 & $-17,23$ & $-44,44$ & $\begin{array}{l}\text { Rio Jequitaí (contato geológico dos } \\
\text { Supergrupos Minas e Espinhaço) }\end{array}$ & Jequitaí & GS \\
\hline 16 & $-17,20$ & $-44,82$ & $\begin{array}{l}\text { Confluência dos Rios das Velhas e São } \\
\text { Francisco }\end{array}$ & Várzea da Palma & GS \\
\hline 17 & $-17,35$ & $-44,95$ & $\begin{array}{l}\text { Rio São Francisco (Ponte Férrea de } \\
\text { Pirapora-Buritizeiro) }\end{array}$ & Pirapora & $\mathrm{BO}$ \\
\hline 18 & $-17,94$ & $-45,11$ & Barra do Rio de Janeiro & Três Marias & GS \\
\hline 19 & $-18,02$ & $-45,11$ & Chapada em Três Marias & Três Marias & $\begin{array}{l}\mathrm{BO} / \mathrm{C} \\
\mathrm{B}\end{array}$ \\
\hline 20 & $-18,22$ & $-45,23$ & Vereda em Felixlândia & Felixlândia & GS \\
\hline
\end{tabular}

Obs: BO - Caminho da Boiada; CB - Corpo de Baile; GS- Grande Sertão Veredas; RM - Recado do Morro.

A escolha dos SG é parte integrante da metodologia proposta por Evangelista (2018) que consiste no levantamento, na classificação e na quantificação dos sítios. Contudo, para o presente trabalho, aborda somente a etapa do levantamento dos SG. Sendo assim, a seleção dos SG foi realizada a partir da leitura das obras rosianas e, consequentemente, da descrição dos lugares por Guimarães Rosa. Além disso, os autores acharam importante realizar a análise dos Marcos Territoriais do CGR. Tais informações foram reforçadas pelos trabalhos de campo que auxiliaram a identificar outros sítios relevantes, ou seja, locais dotados de valor intrínseco, cultural, estético, econômico, funcional, científico e educativo que pudessem contribuir para a valorização ambiental e o desenvolvimento sustentável regional. 


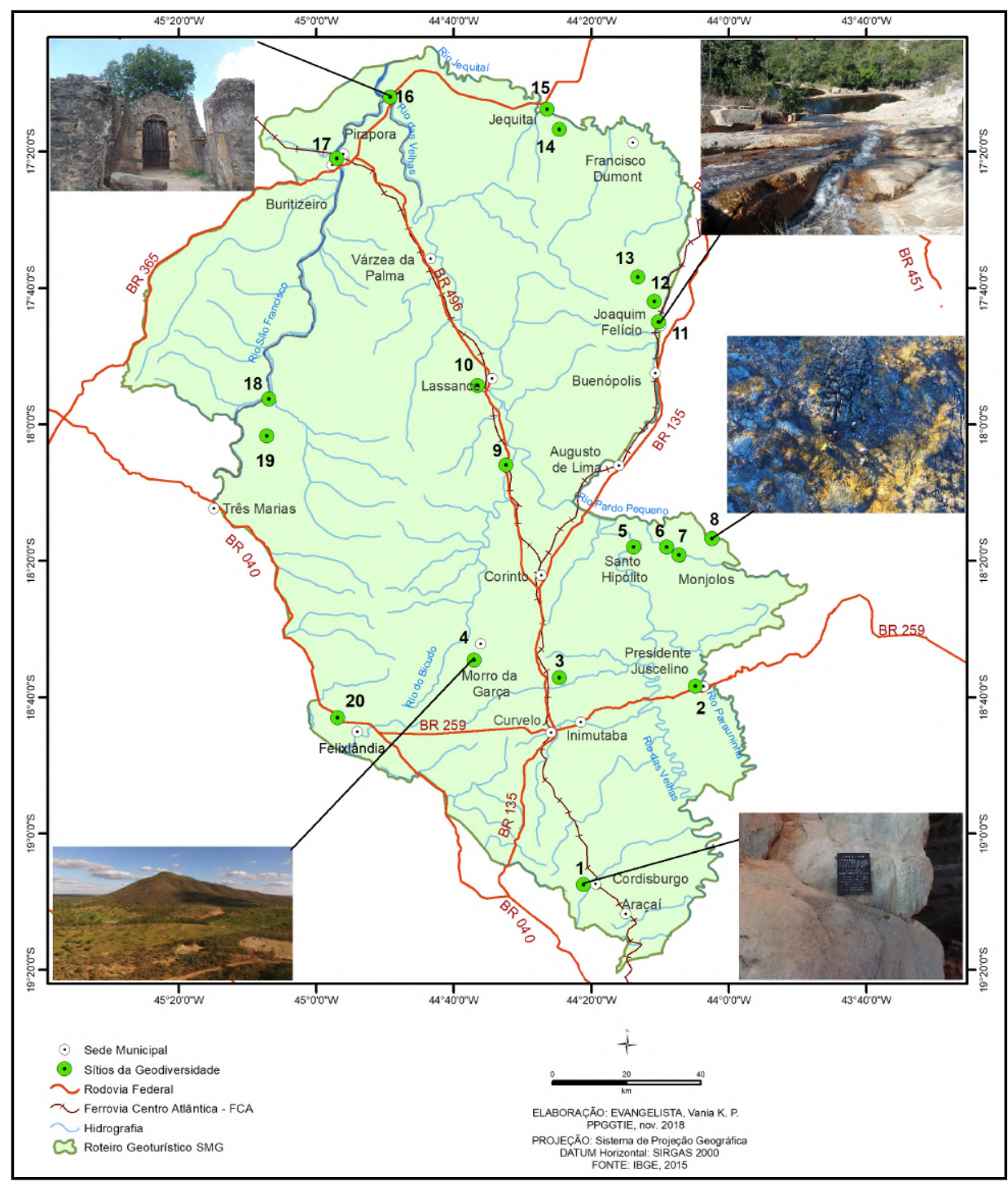

Figura 03: Mapa de localização dos Sítios da Geodiversidade do Roteiro Geoturístico Sertões de Minas Gerais.

A Lapa Nova do Maquiné (SG1) ou Gruta do Maquiné (Figura 04) está localizada em Cordisburgo. É uma cavidade natural subterrânea com $650 \mathrm{~m}$ de extensão e $18 \mathrm{~m}$ de desnível que chamou atenção de pesquisadores como Peter W. Lund (1834) e Álvaro da Silveira (IBGE, 1939). Diante de sua beleza e relevância histórico-científica, a gruta faz parte do Monumento Natural Estadual Peter Lund, desde 2005. 


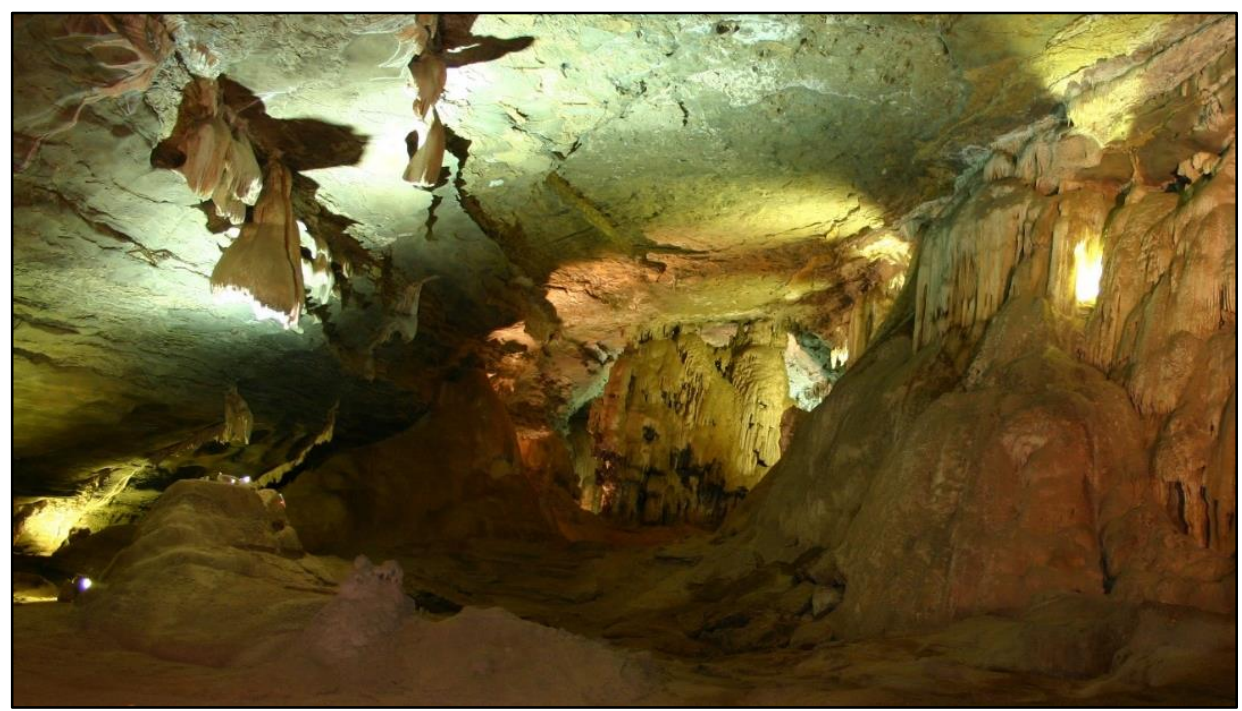

Figura 04: Aspecto geral de um salão da Lapa Nova do Maquiné, em Cordisburgo, Minas Gerais (Foto: L.E.P. Travassos).

O SG2 também compreende uma cavidade natural subterrânea, a Gruta das abelhas, localizada no Morro do Coroado, em Presidente Juscelino, na margem direita do Rio Paraúna. A gruta apresenta pinturas rupestres e várias colmeias, daí o seu nome. A Lapa dos Mosquitos (SG3), situada em Curvelo, também foi visitada e mencionada por Peter W. Lund em meados do século XIX; apresenta três entradas, uma claraboia e desenvolvimento horizontal de aproximadamente $1.000 \mathrm{~m}$ que comporta galerias, salões, níveis superiores, um curso d'água meandrante e seu sumidouro (PROUS, 2005).

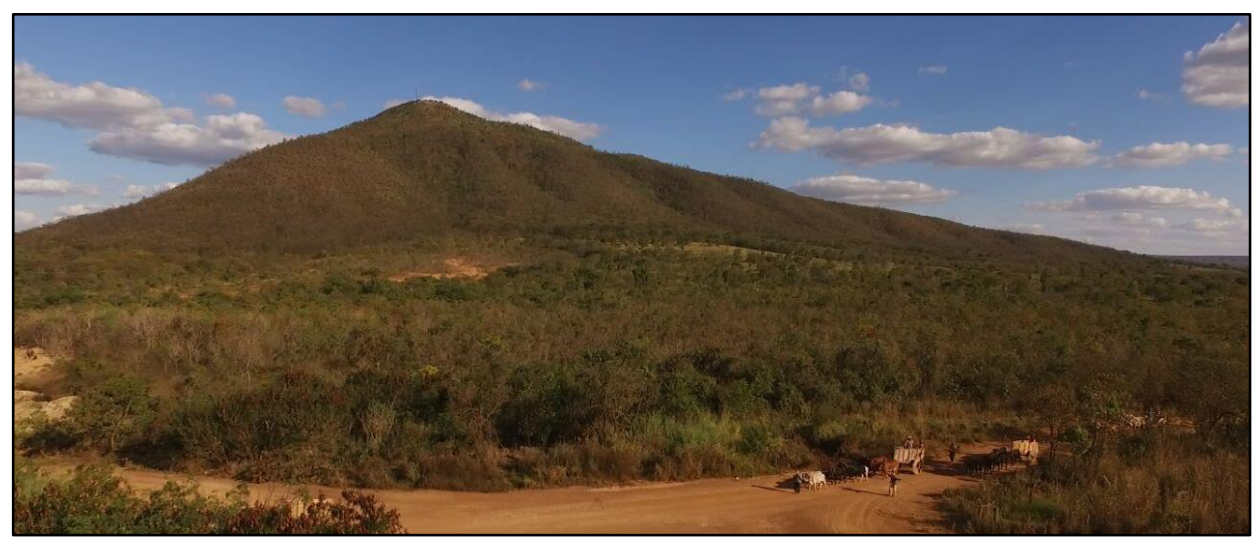

Figura 05: Vista geral do Morro da Garça (Foto: Grupo Caju). 
O Morro da Garça (SG4), situado no município homônimo, é considerado por muitos uma forma singela e, ao mesmo tempo, imponente por ser avistado de longe. Nas obras de Guimarães Rosa, é sempre uma referência para os viajantes. O SG4 é uma geoforma elíptica e relictual da paisagem com aproximadamente 1,6 km de diâmetro e altitude em torno de $950 \mathrm{~m}$ (Figura 05).

O Rio das Velhas, como descrito por Guimarães Rosa, é um rio de belas paisagens e várzeas. Assim, diante desses aspectos, considerou-se o Rio das Velhas na Ponte Férrea em Santo Hipólito (SG05) como ponto de referência de um local dotado de valores intrínseco, estético, educativo/científico. O sítio se localiza na atual rodovia MG220 que liga o município de Santo Hipólito até Corinto (Figura 06).

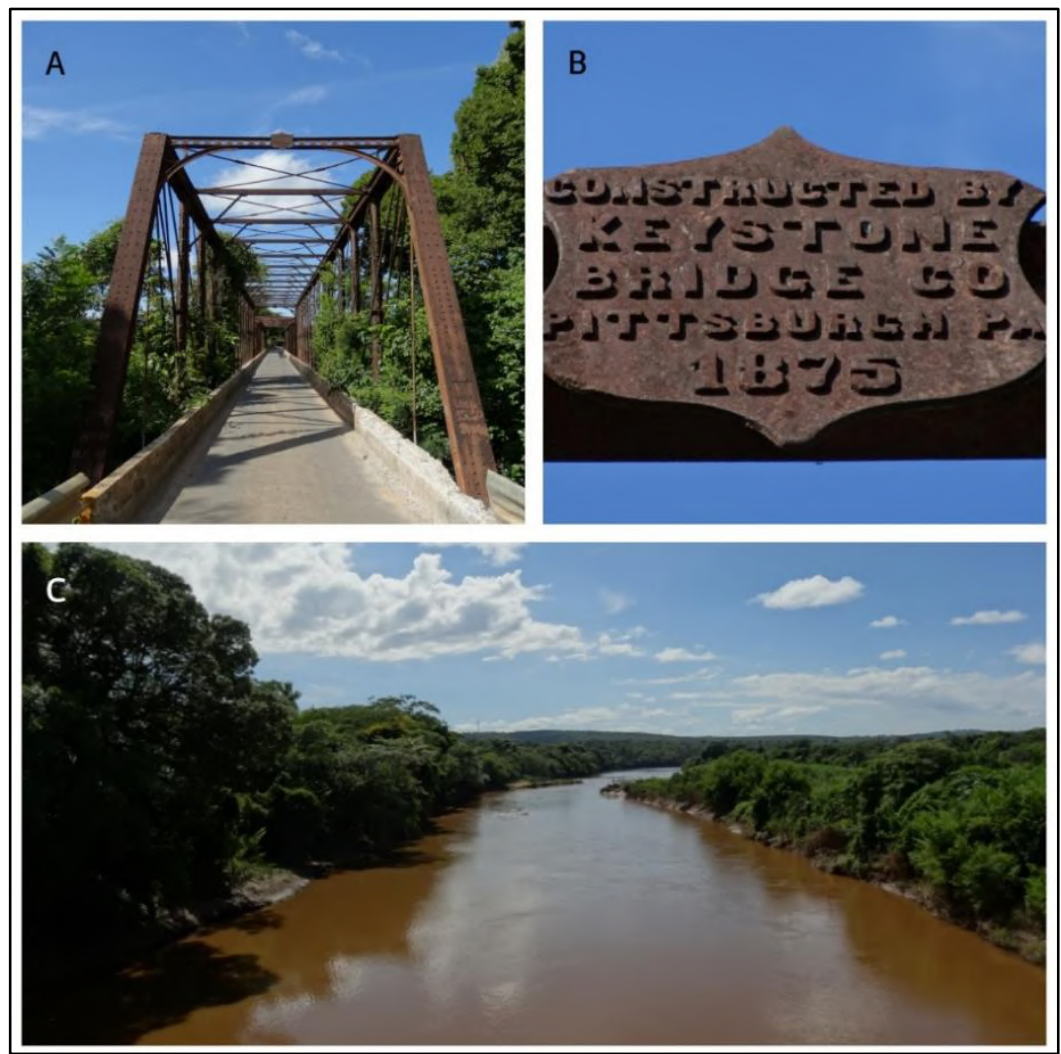

Figura 06: A) Vista da ponte sobre o Rio das Velhas. B) Placa com a data de construção da ponte. C) Vista parcial do Rio das Velhas (Fotos: L.E.P. Travassos).

O município de Monjolos, localizado em uma zona de transição geológica entre os Supergrupos Espinhaço e São Francisco apresenta vários elementos notáveis da 
geodiversidade (Figura 07). Entre eles destacam-se a Lapa do Rozilho (SG6), o Maciço e o Rio Pardo Pequeno (SG7) e o Mirante em Rodeador (SG8).
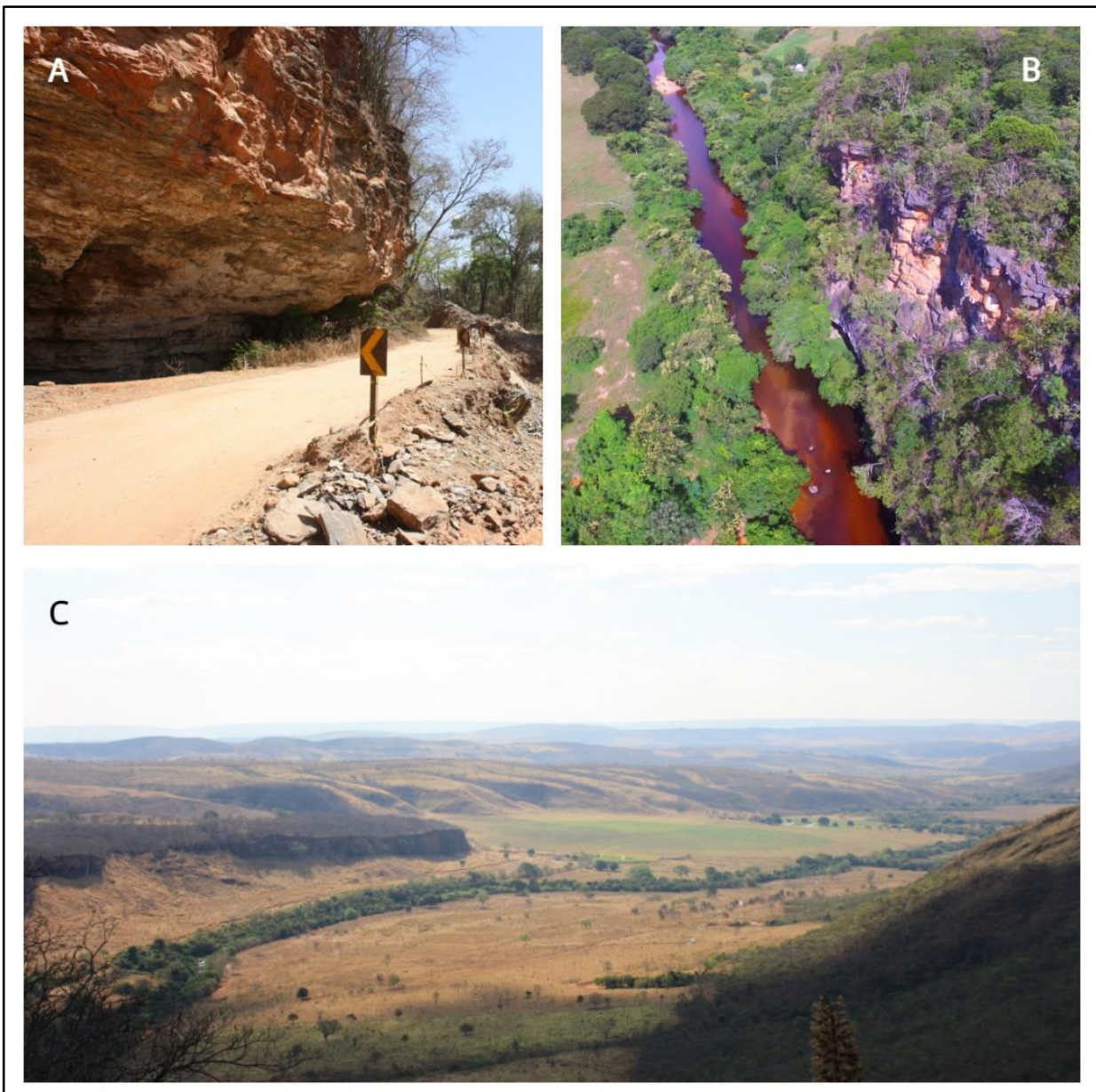

Figura 07: A) Maciço da Lapa do Rozilho antes do asfaltamento da estrada. B) Vista aérea do rio Pardo Pequeno e maciço próximo. C) Vista panorâmica do contato litológico entre os carbonatos e quartzitos em Rodeador (Fotos: L.E.P. Travassos).

O SG6 compreende uma cavidade natural subterrânea que atualmente encontrase reduzida a um salão, cujas dimensões são de $20 \mathrm{~m}$ de extensão, $80 \mathrm{~m}$ de largura e $9 \mathrm{~m}$ de altura (IBGE, 1939). Já o SG7, localizado às margens do Rio Pardo Pequeno, conta com o registro de 7 cavidades naturais subterrâneas (CECAV, 2018). Já o mirante (SG8) compreende uma região de afloramentos calcários e um extenso campo de lapiás. 
Na região central do Estado de Minas Gerais às margens da rodovia BR-496 e da Ferrovia Centro-Atlântica (FCA), encontra-se a Serra do Bicudo (SG9). Localizada no distrito de Beltrão (Corinto) a Serra apresenta contas altimétricas acima dos $1.000 \mathrm{~m}$ tornando-a importante divisor regional de águas, contribuindo para a bacia do Rio das Velhas com rios perenes e intermitentes. Situado a noroeste do SG9 encontra-se a Gruta da Ponta (SG10), com aproximadamente 109,70 m de desenvolvimento linear, localizada na região que foi denominada Carste Engenho Velho conforme Cassimiro et al. (2006).

No limite leste da área de estudo encontra-se a Serra do Cabral, uma geoforma com características geológicas do Supergrupo Espinhaço, localizada no Supergrupo São Francisco e que apresenta um geopatrimônio relevante. Por esse motivo, favoreceu a seleção de três sítios da geodiversidade (SG): a Cachoeira do Boqueirão (SG11), os Metarenitos da Serra do Cabral (SG12) e a Lagoa Azul (SG13), destacados na Figura 08.

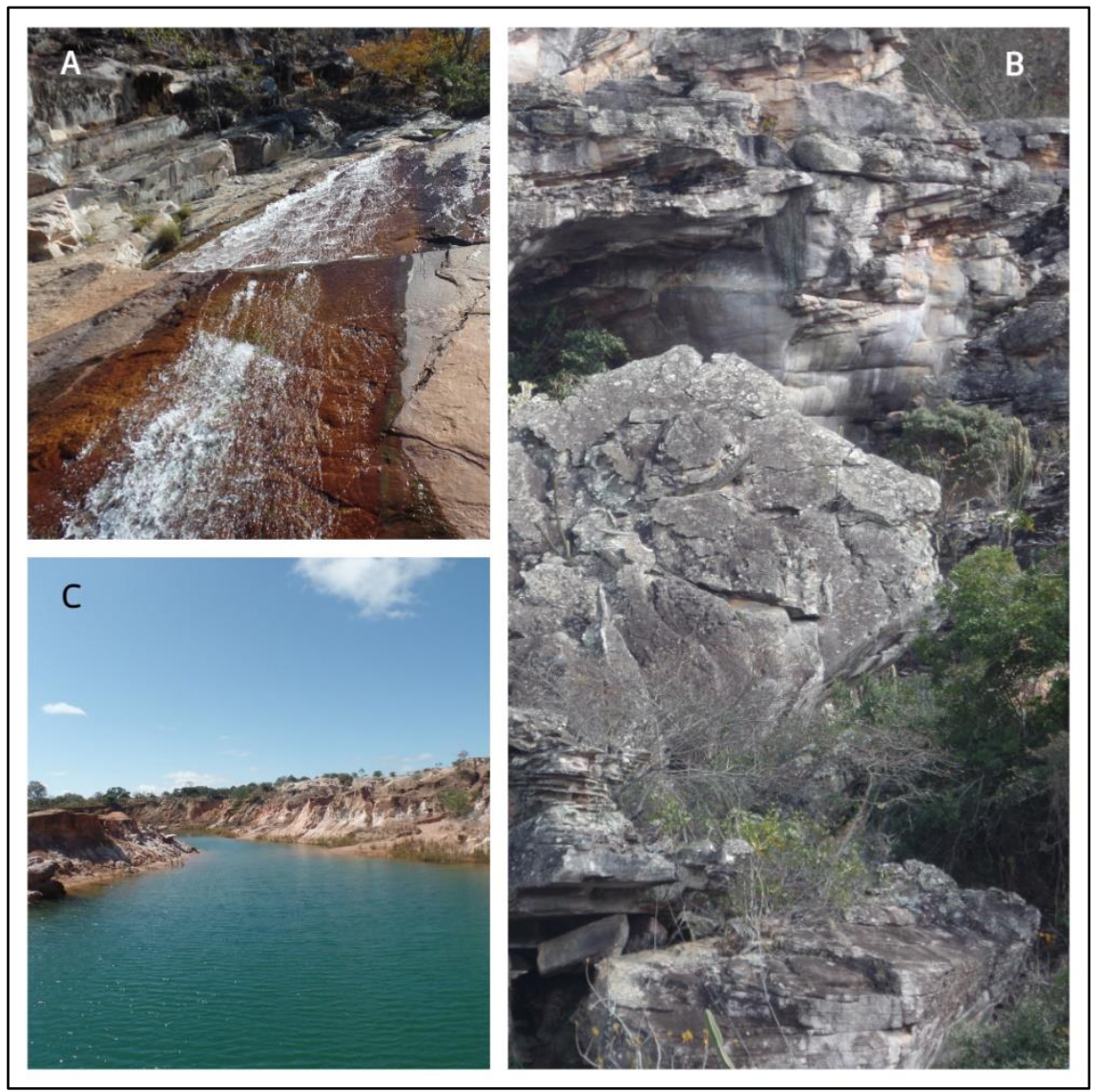

Figura 08: A) Afloramento em parte da Cachoeira do Boqueirão. B) Os Metarenitos da Serra do Cabral. C) Vista parcial da Lagoa Azul (Fotos: V.K. Evangelista). 
O SG11 está situado no centro urbano de Joaquim Felício e é formado por dois cursos d'água cujas nascentes estão na Serra do Cabral a cerca de $1.250 \mathrm{~m}$ de altitude. Apresenta-se como um dos SG mais representativos no Roteiro Geoturístico SMG. Ao norte desse SG, entre Joaquim Felício e Francisco Dumont, encontram-se os metarenitos (SG12) que se destacam na paisagem. E a noroeste, é possível localizar no topo da Serra do Cabral, o SG13, uma cava inundada de um garimpo de quartzo abandonado.

Na porção nordeste estão localizados o Mirante na Serra do Boqueirão e o Rio Jequitaí, respectivamente o SG14 e o SG15 (Figura 09). O Mirante situado aos $800 \mathrm{~m}$ de altitude proporciona uma visão singular da Serra do Cabral (sudeste) e da Serra da Água Fria (sudoeste), ambas com nascentes tributárias do Rio Jequitaí. Descrito por Guimarães Rosa como um rio de travessias, o Rio Jequitaí é extremamente relevante em uma região de clima árido. Já o SG15 marca o contato geológico dos Supergrupos São Francisco e Espinhaço.

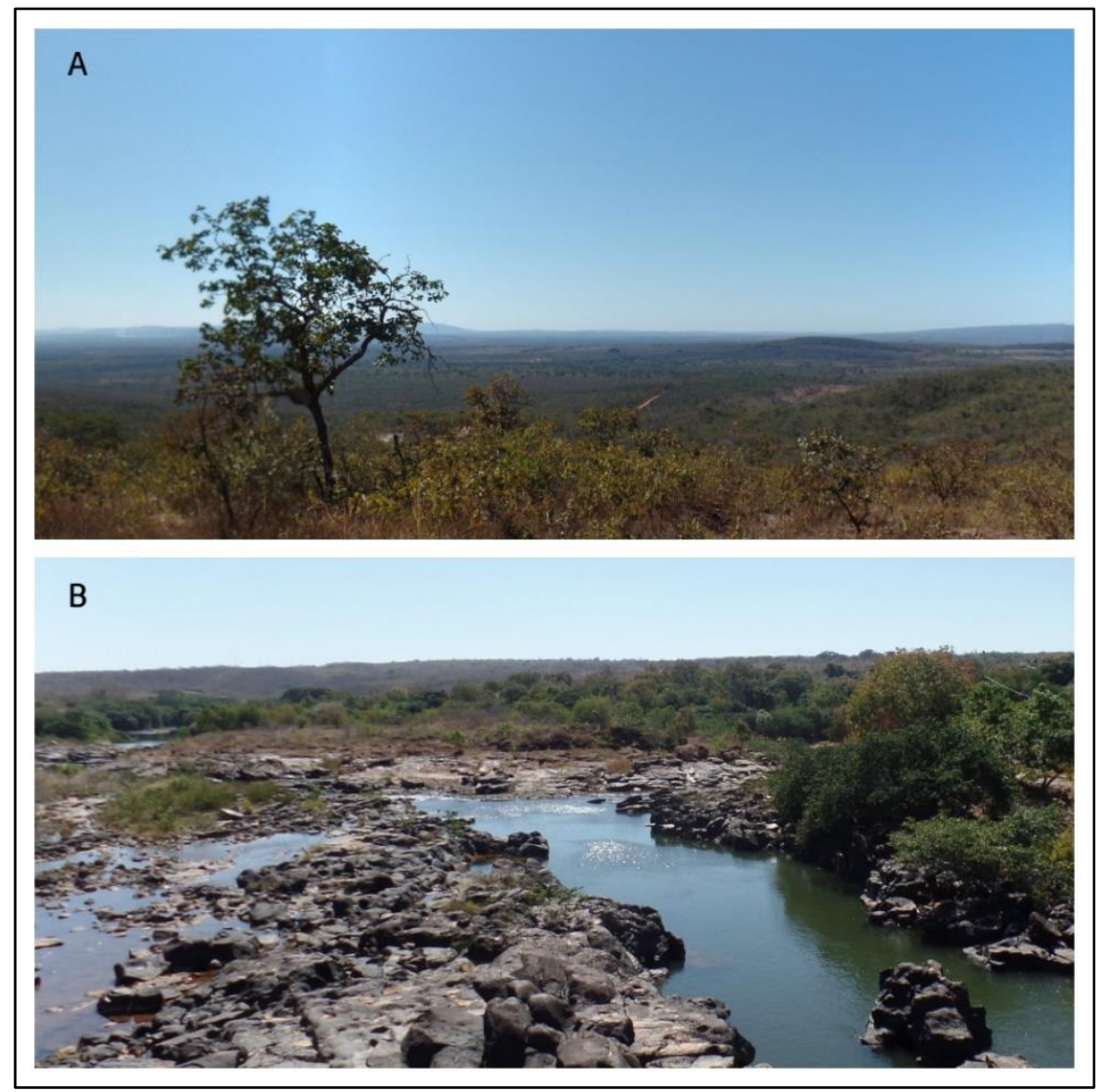

Figura 09: A) Vista panorâmica a partir do Mirante na Serra do Boqueirão B) Afloramentos no leito do Rio Jequitaí (Fotos: V.K. Evangelista). 
No limite entre Várzea da Palma e Pirapora, destaca-se o distrito de Barra do Guaicuí, local onde ocorre a confluência do Rio das Velhas e do Rio São Francisco (SG16). Tal região é composta por vários elementos culturais e históricos como as ruínas da Igreja Bom Jesus de Matozinhos. A montante do ponto situa-se o SG17 (Rio São Francisco / Ponte Férrea), limite geográfico entre os municípios de Pirapora e Buritizeiro que tem acesso facilitado pela ponte Marechal Hermes (da EFCB), inaugurada em 1922 (GIESBRECHT, 2018). Esse ponto é marcado pelas extensas margens do Rio São Francisco como menciona Guimarães Rosa ao considerá-lo como um “pau grosso”.

Ao sul desse SG17 encontra-se outro interflúvio do Rio São Francisco, a região denominada de Barra do Rio de Janeiro (SG18). O Rio de Janeiro é um afluente da margem direita do Rio São Francisco com nascente há cerca de 900 m na porção sudeste da Serra de Santa Rita (Lassance). Essa região também é descrita pelo escritor como local onde o personagem Rioboaldo viveu sua adolescência e é também o ponto de partida da Boiada, em 1952, com destino a Fazenda Nossa Senhora de Fátima (atual Fazenda São Francisco), em Araçaí. Nesse trajeto realizado por Guimarães Rosa (1952), as Chapadas em Três Marias (SG19) se destacam por sua estrutura de topo plano que favorece a agricultura em larga escala e a silvicultura, atividades muito presentes na região.

As veredas são uma fitofisionomia marcante no sertão mineiro rosiano. Ao longo da rodovia BR-040, entre os municípios de Três Marias e Felixlândia, encontra-se a Vereda em Felixlândia (SG20). Constantemente visualizadas e de fácil acesso, as veredas (Figura 10) são típicas de áreas que apresentam solos mal drenados ao longo de fundo de vales e ocupadas, predominantemente, pela palmeira arbórea (Mauritia flexuosa).

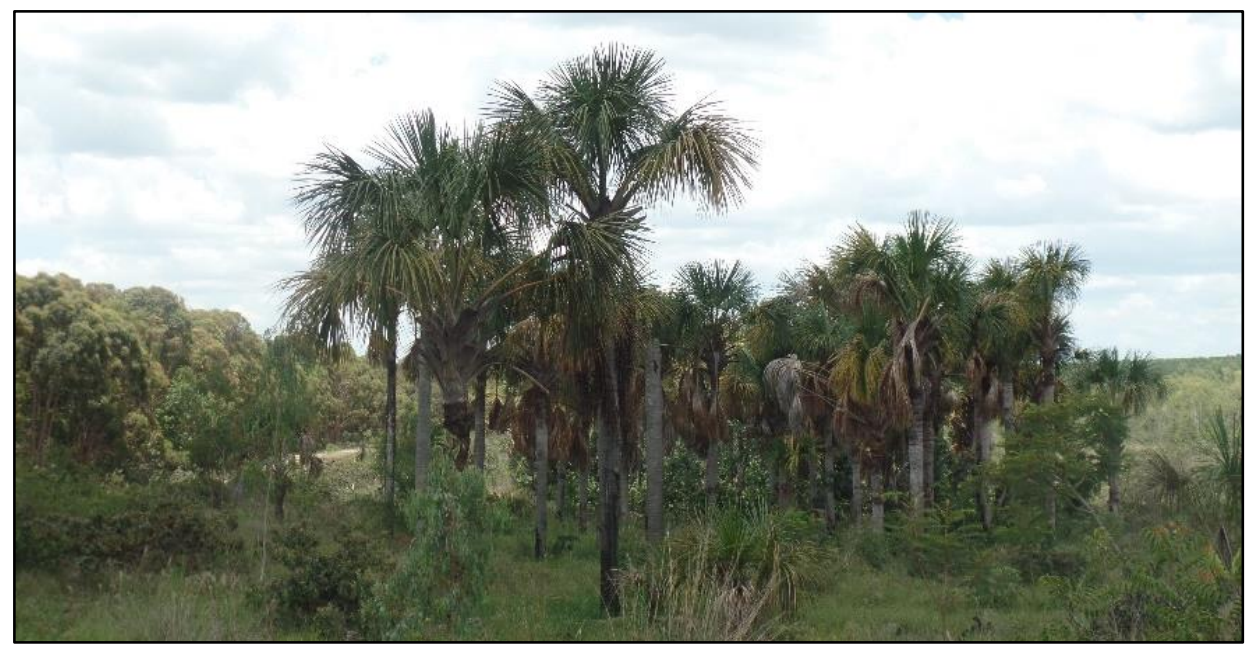

Figura 10: Vista de uma das inúmeras veredas da região de Felixlândia, Minas Gerais (Foto: V.K. Evangelista). 


\section{Práticas geoturísticas no sertão mineiro de Guimarães Rosa}

Diante da relevância intrínseca, científica, turística e de uso/gestão apresentada pelos SG nesta pesquisa, sugere-se que sejam tomadas iniciativas em prol desse geopatrimônio. Destaca-se que algumas ações isoladas já vêm ocorrendo a exemplo da candidatura do Morro da Garça a categoria de Sítio Geomorfológico na SIGEP ${ }^{1}$ (2006). Embora a proposta não tenha sido aprovada, sua importância cultural e histórica foi reconhecida pelos avaliadores. Ressalta-se que parte da Serra do Cabral está inserida no roteiro que integra o Parque Estadual da Serra do Cabral. Entretanto, algumas áreas com elevado potencial para conservação ainda não contam com iniciativas para efetivar a geoconservação dos sítios da geodiversidade. Dentre as regiões estão a Serra do Boqueirão e os rios de Janeiro, São Francisco, das Velhas e Jequitaí. Dessa forma, ao elaborar propostas de valorização da geodiversidade e do geopatrimônio, busca-se por meio do geoturismo promover a geoconservação e o desenvolvimento sustentável regional dessas áreas.

Cinco rotas geoturísticas foram propostas com o objetivo de desenvolver estratégias geoturísticas (rotas e folders interpretativos) que integrem os sítios da geodiversidade selecionados. Nas rotas devem ser valorizados os aspectos culturais e históricos das regiões onde estão localizados os sítios. A pesquisa propõe as rotas conforme demonstrado pela Tabela 2.

Nessa proposta das rotas foram consideradas as principais vias de acesso (em sua maioria pavimentadas), os museus, as casas de cultura e a infraestrutura dos centros urbanos mais próximos. Além disso, cada rota deve contar com um folder interpretativo que apresenta informações relevantes relacionados aos aspectos históricos e culturais, bem como a geologia, a geodiversidade, o geopatrimônio, a geoconservação e o geoturismo. O folder (Figura 11) integra todas as rotas, pois apresenta alguns locais e/ou paisagens relevantes por meio de ilustrações que instiguem o geoturista a visitar todas as rotas (Figura 12).

Tabela 02. Rotas geoturísticas no Roteiro Geoturístico Sertões de Minas Gerais.

\begin{tabular}{|c|c|c|c|}
\hline ROTA & $\begin{array}{c}\text { EXTENSÃO } \\
(\text { KM })\end{array}$ & MUNICÍPIOS & $\begin{array}{c}\text { ATRATIVOS TURÍSTICOS, } \\
\text { CIENTÍFICOS/EDUCACIONAIS }\end{array}$ \\
\hline Rosiana & 6 & Cordisburgo & $\begin{array}{c}\text { Museu Casa Guimarães Rosa, Estação } \\
\text { Ferroviária de Cordisburgo, Portal Grande } \\
\text { Sertão e Gruta Nova do Maquiné. }\end{array}$ \\
\hline do Carste & 85 & $\begin{array}{c}\text { Santo Hipólito e } \\
\text { Monjolos }\end{array}$ & $\begin{array}{c}\text { Estação Ferroviária de Santo Hipólito, Gruta } \\
\text { do Pau Ferro, Mirante em Rodeador e Campo } \\
\text { de lapiás }\end{array}$ \\
\hline dos Riachos & 85 & $\begin{array}{c}\text { Joaquim Felício e } \\
\text { Francisco Dumont }\end{array}$ & $\begin{array}{c}\text { Estação Ferroviária de Joaquim Felício, } \\
\text { Cachoeira do Boqueirão, Mirante do Cristo e } \\
\text { Piscinas em Francisco Dumont }\end{array}$ \\
\hline
\end{tabular}

Continua...

\footnotetext{
${ }^{1}$ Comissão Brasileira de Sítios Geológicos e Paleobiológicos - SIGEP
} 


\begin{tabular}{|c|c|c|c|}
\hline ROTA & $\begin{array}{c}\text { EXTENSÃO } \\
\text { (KM) }\end{array}$ & MUNICÍPIOS & $\begin{array}{c}\text { ATRATIVOS TURÍSTICOS, } \\
\text { CIENTÍFICOS/EDUCACIONAIS }\end{array}$ \\
\hline Grande Sertão & 50 & $\begin{array}{c}\text { Pirapora e Várzea } \\
\text { da Palma }\end{array}$ & $\begin{array}{c}\text { Ponte Marechal Hermes, Cachoeira do Rio } \\
\text { São Francisco, Benjamim Guimarães; e Barra } \\
\text { do Guaicuí. }\end{array}$ \\
\hline da Boiada & 150 & $\begin{array}{c}\text { Morro da Garça, } \\
\text { Felixlândia e Três } \\
\text { Marias }\end{array}$ & $\begin{array}{c}\text { Casa de Cultura do Sertão, Mirante do Morro } \\
\text { da Garça, Serra do Grotão e Museu } \\
\text { Manuelzão. }\end{array}$ \\
\hline
\end{tabular}

Fonte: Dados da pesquisa.
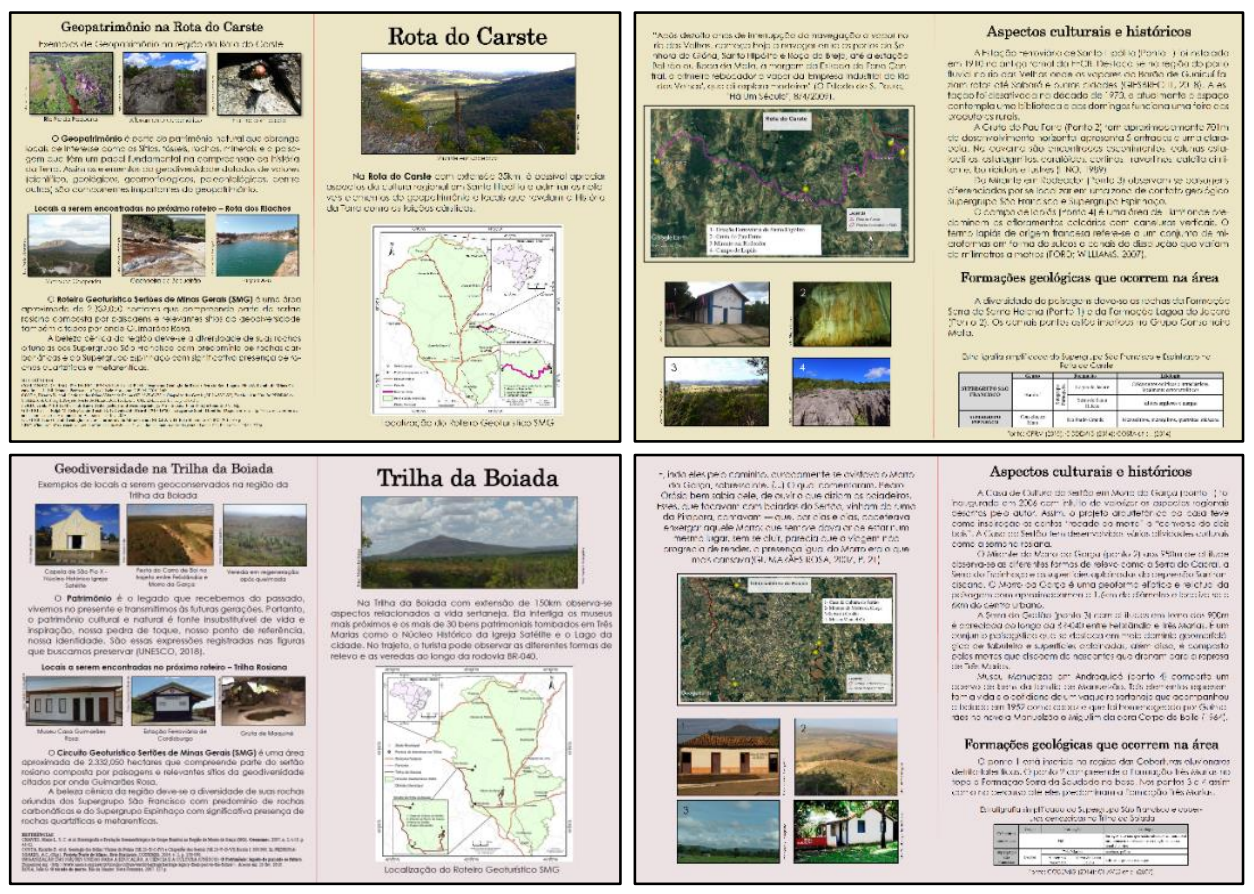

Figura 11: Detalhe de dois dos folders de divulgação das Rotas Geoturísticas no Roteiro Geoturístico Sertões de Minas Gerais. A impressão é realizada em tamanho A4 frente e verso, gerando um produto em tamanho A5. Para todas as rotas o material apresenta aspectos do geopatrimônio, bem como aspectos culturais e históricos.

Fonte: Elaborado pelos autores. 


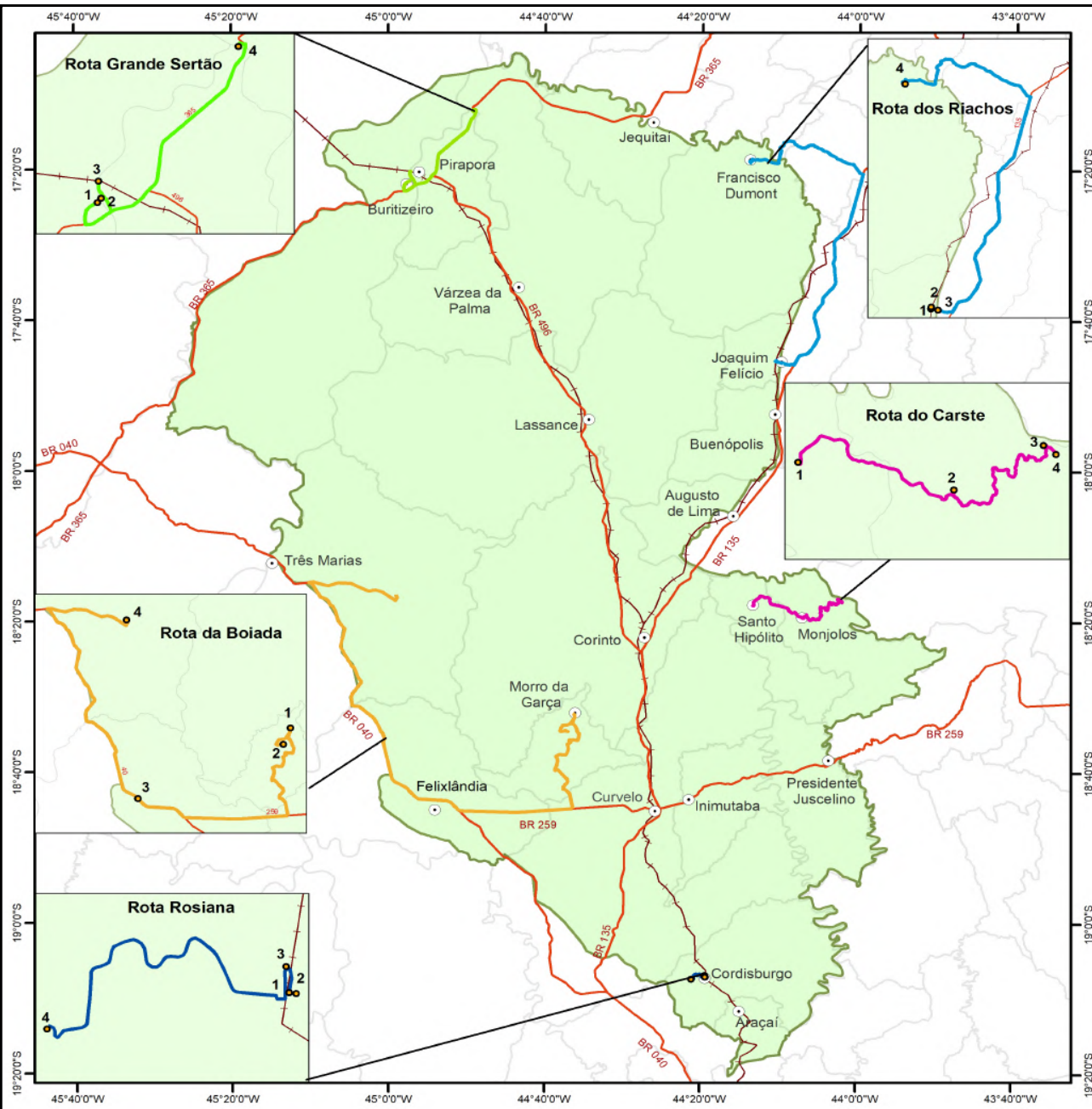

Pontos e Rotas
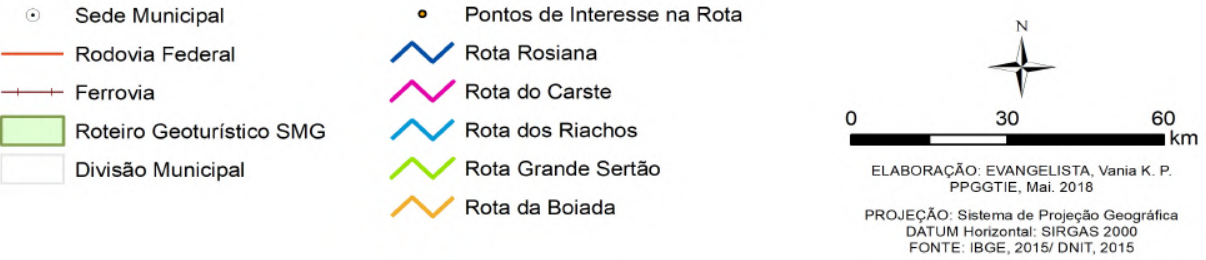

Figura 12. Mapa de localização do Sítios da Geodiversidade nas Rotas do Roteiro Geoturístico Sertões de Minas Gerais

Fonte: Elaborado pelos autores. 


\section{Considerações Finais}

O sertão mineiro é apresentado ao mundo pelo estilo modernista e pósmodernista de Guimarães Rosa que descreve e relata, para muitos, uma realidade desconhecida e marcada por elementos metafísicos, sentimentos, emoções e narrativas. A abordagem rosiana de utilizar a geografia como fonte de investigação na literatura para compreender as relações homem-meio retoma temas clássicos da geografia tradicional como a paisagem, assim como os relatos das descobertas dos lugares feitas pelos viajantes durante o período das grandes navegações.

Esse sentimento de descobertas, e ao mesmo tempo de busca pelo contato com direto com as áreas naturais, é retomado ao longo do século XX ao apreciarem a beleza cênica e obterem uma sensação de bem-estar. Entretanto, o intenso fluxo da atividade turística para essas regiões, aliado a expressiva exploração dos recursos naturais gerou perdas significativas desencadeando em uma proposta de conservar os elementos do patrimônio natural. Neste contexto, observa-se a valorização dos elementos da geodiversidade, bem como de seu geopatrimônio que é composto por locais dotados de relevância intrínseca, cultural, estética, econômica, científica, educativa e turística. $\mathrm{Na}$ região de estudos percebe-se que, além de valorizar, é necessário conservar as geoformas por meio de ações geoturísticas.

Pautados no conceito de é necessário conhecer tais elementos que para se conservar, a pesquisa selecionou e inventariou 20 Sítios da Geodiversidade no cenário descrito por Guimarães Rosa como representantes de paisagens de Minas Gerais. Após essa seleção, foram propostas estratégias geoturísticas associadas às rotas por meio de folders interpretativos que trazem informações relacionadas aos contextos geológicos, históricos e culturais regionais. Destaca-se, ainda, que os SGs ao longo das rotas visam a valorização dos elementos da geodiversidade e o desenvolvimento sustentável regional, buscando inserir moradores e demais agentes locais na conservação do patrimônio natural.

\section{Referências}

ALLAN, M. Toward a better understanding of motivations for a geotourism experience: A self-determination theory perspective. 2011. 316f. Tese (Doutorado em Filosofia) - School of Marketing, Tourism and Leisure Faculty of Business and Law Edith Cowan University Western Australia. Disponível em: http://ro.ecu.edu.au/theses/438. Acesso em 03 nov. 2016.

AMORIM FILHO, O. B. Literatura de explorações e aventuras: as "viagens extraordinárias" de Júlio Verne. Sociedade \& Natureza, v.20, n.2, p.107-119, dez. 2008. ASSOCIAÇÃO EUROPEIA PARA A CONSERVAÇÃO DO PATRIMÔNIO
GEOLÓGICO (ProGEO). Conserving our shared Geoheritage - a protocol on Geoconservation principles, sustainable site use, management, fieldwork, fossil and mineral collecting. 2011. Disponível em: http://www.sigeaweb.it/geoheritage/ documents/progeoprotocol-definitions-20110915.pdf. Acesso em 21 out. 2018. 
BERTRAND, G. Paysage et géographie physique globale. Esquisse méthodologique. Revue géographique des Pyrénées et du Sud-Ouest, v. 39, n.3, p. 249-272, 1968.

BRILHA, J. B. R. Patrimônio Geológico e Geoconservação: A conservação da natureza na sua vertente geológica. Braga: Palimage Editores, 2005. 183p.

BRILHA, José B. R. Inventory and Quantitative Assessment of Geosites and Geodiversity Sites: a Review. Geoheritage, n.8, p.119-134, 2016.

BUREK, C. V.; PROSSER, C. D. The history of geoconservation: an introduction. In: The History of Geoconservation. London: Geological Society, Special Publications, Cap. 1, v.300, p. 1-6, 2008.

CAÑADAS, S.; FLAÑO, R. Geodiversidad: concepto, evaluación y aplicación territorial. El caso de Tiermes Caracena (Soria). Boletín de la A.G.E, n.45, p.79-98, 2007. Disponível em: http://www.age-geografia.es/ojs/index.php/bage/issue/view/60. Acesso em 13 nov. 2018.

CARCAVILLA, L. U.; DURÁN, J. J. V.; LÓPEZ-MARTÍNEZ, J. J. Geodiversidad: concepto y relación com el patrimonio geológico. Geo-Temas, n. 10, p. 1299-1303, 2008. VII Congreso Geológico de España. Las Palmas de Gran Canaria. Disponível em: http://www.igme.es/patrimonio/descargas/concepto_Geodiversidad.pdf. Acesso em 13 out. 2018.

CASSIMIRO, R. et al. Prospecção e mapeamento do Carste Engenho Velho, município de Lassance, Minas Gerais. In: SIMPÓSIO NACIONAL DE GEOMORFOLOGIA, 6, 2006. Anais... Goiânia: UFG, 2006, p. 1-7. Disponível em: http://lsie.unb.br/ugb/ sinageo/6/5/235.pdf. Acesso em 22 fev. 2018.

CECAV - Centro Nacional de Pesquisa e Conservação de Cavernas. Cadastro Nacional de Informações Espeleológicas (CANIE). 2017. Disponível em: http://www.icmbio. gov.br/cecav/canie.html . Acesso em: 29 jul.2018.

CLAVAL, P. “A VOLTA DO CULTURAL” NA GEOGRAFIA. Mercator, v.1, n.1, 2002.

CLAVAL, P. O papel da Nova Geografia na ação da compreensão humana. In:

ROSENDAHL, Z.; CORREA, R.L. (Orgs.). Matrizes da Geografia Cultural. Rio de Janeiro: EdUERJ, p. 35-86, 2001.

COLFERAI, D.I.G.; GOMES, M.F.V.B. A literatura como instrumento para uma geografia do campo, 2009. Disponível em: http://www.diaadiaeducacao.pr.gov.br/ portals/pde/arquivos/1605-8.pdf Acesso em 22 fe.2018.

COLLOT, M. Pour une géographie littéraire: une lecture d'Archipel de Claude Simon. Carnets: revue électronique d'études françaises. v.2, n. 3, p. 8-23, 2015.

COMISSÃO BRASILEIRA DE SÍTIOS GEOLÓGICOS E PALEOBIOLÓGICOS (SIGEP). 2006. Sítio Morro da Garça (MG). Disponível em: http://sigep.cprm. gov.br/propostas/Morro_da_Garca_MG.htm . Acesso em 11 dez. 2018. 
CORREAA, R.L. Paisagem e Geografia. In: NEGREIROS, C.; LEMOS, M.; ALVES, I.

(Orgs.). Literatura e Paisagem em diálogo. Rio de Janeiro: Makunaima, 2012.p. 29-43.

CUNHA, C.M.F. A(s) geografia(s) da literatura: do nacional ao global. Guimarães: Opera Omnia, 2011. 118p.

DOWLING, R.; NEWSOME, D. The future of geotourism where to from here. In:

NEWSOME, D.; DOWLING, R. (Eds). Geotourism: the tourism of geology and landscape. Oxford: Goodfellow, 2010. p. 231-244.

ERIKSTAD, L. History of Geoconservation in Europe. In: BUREK, C.V.; PROSSER C.D. (Eds.). The history of geoconservation. London: The Geological Society, 2008. p.249-256.

EVANGELISTA, V.K.P. Geografia e literatura: uma aproximação para o desenvolvimento do geoturismo no sertão mineiro de Guimarães Rosa. 2018. 208f. Tese (Doutorado em geografia) - Pontifícia Universidade Católica de Minas Gerais, Belo Horizonte.

FERRÉ, A. O problema e os problemas da geografia literária. Documentos da Associação Internacional de Estudos Franceses, n. 6, p. 145-164, 1954.

FERREIRA, H. M. A literatura na sala de aula: uma alternativa de ensino transdisciplinar. 2007. 377f. Tese (doutorado em educação) - Universidade Federal do Rio Grande do Norte, Natal.

FONT, J. N. Geografía humanista y paisaje. Anales de Geografia de la Universidad Complutense, n.5. El Univ, Complutense, p.93-97, 1985.

GIESBRECHT, R.M. Estações do Brasil: E. F. Central do Brasil (1910-1975) - estação de Pirapora. Disponível: http://www.estacoesferroviarias.com.br/efcb_mg_ramais pirapora.htm. Acesso em: 15 out. 2018.

GRAY, M. Geodiversity: valuing and conserving abiotic nature. 2.ed. Chichester: WileyBlackwell, 2013. 495p.

GRAY, M. Geodiversity: valuing and conserving abiotic nature. London: John Wiley \& Sons Ltd., 2004. 450p.

GUIMARÃES, R. L. Mapeamento geomorfológico do carste da região de Monjolos, Minas Gerais. 2012. 157f. Dissertação (Mestrado) - Pontifícia Universidade Católica de Minas Gerais, Programa de Pós-Graduação em Geografia - Tratamento da Informação Espacial, Belo Horizonte.

HOSE, T. European Geotourism - Geological Interpretation and Geoconservation Promotion for Tourists. Geological heritage: its conservation and management. Madrid: Instituto Tecnologico Geominero de Espana, 2000. p.127-146.

HOSE, T. The English Origins of Geotourism (as a Vehicle for Geoconservation) and Their Relevance to Current Studies. Acta Geographica Slovenica, v.2, n.51, p.343 - 360, 2011.

IBGE - Instituto Brasileiro de Geografia e Estatística. As Grutas em Minas Gerais. $1^{\text {a }}$ Ed. Belo Horizonte: Oficinas Gráficas da Estatística, 1939, 333p. 
IBGE - Instituto Brasileiro de Geografia e Estatística. Atlas das representações literárias de regiões brasileira. Rio de Janeiro: IBGE, v. 1, 2006, 88p.

INSTITUTO DO PATRIMÔNIO HISTÓRICO E ARTÍSTICO NACIONAL (IPHAN).

Patrimônio mundial: fundamentos para seu reconhecimento. A convenção sobre proteção do patrimônio mundial, cultural e natural, de 1972: para saber o essencial. Brasília: IPHAN, 2008.80 p.

KOZLOWSKI, S. Geodiversity. The concept and scope of geodiversity. Polonia: Przeglad Geologiczny, v. 52, n.8/2, p. 833-837, 2004.

LÉVY, B. Géographie et littérature. In: LÉVY, B.; MATOS, R.; SAFFESTIN, S. (Auts.). Le tourisme à Genève. Une géographie humaine. Metropolis: Genève, 2002. p.19-45

LÉVY, B. Géographie et littérature. Une synthèse historique. Le Globe, v.146, p.25-52, 2006.

LIMA, F. F.; VARGAS, J.C. Geoconservação, geoturismo e geoparques. Florianópolis: Centro Tecnológico, Departamento de Engenharia Sanitária e Ambiental, 2014. 53 p.

LUCHIARI, M.T.D.P.A. (RE) Significação da paisagem no período contemporâneo. In: ROSENDAHL, Z.; CORREA, R. L. (Orgs.). Paisagem, imaginário e espaço. Rio de Janeiro: EdUERJ, 2001. p. 9-28.

MARANDOLA JR, E; GRATÃO, Lúcia H. B. (Orgs.). Geograficidade, Poética e Imaginação. In: Geografia e Literatura: ensaios sobre geograficidade, poética e imaginação. Londrina: Eduel, 2010. p.7-14.

NUCLEO INTERINSTITUCIONAL DE LINGUISTICA COMPUTACIONAL NILC/USP. Modernismo. Disponível em: http://www.nilc.icmc.usp.br/nilc/literatura/ modernismo1.htm. Acesso em: 11 nov. 2018.

PEREIRA, R.G.F.A. Geoconservação e desenvolvimento sustentável na Chapada Diamantina (Bahia - Brasil). 2010. 317f. Tese (Doutorado em Geologia) - Universidade do Minho, Escola de Ciências, Braga. Disponível em: http://repositorium.sdum. uminho.pt/bitstream/1822/10879/1/Tese.pdf. Acesso em: 15 dez. 2018.

PINHEIRO NETO, J.E. Geografia e Literatura: a paisagem geográfica e ficcional em Morte e Vida Severina de João Cabral de Melo Neto. Boletim Campineiro de Geografia, v.2, n.2, p. 322-340, 2012.

PROUS, X. Entradas de cavernas: interfaces de biodiversidade entre ambientes externos e subterrâneos Distribuição dos artrópodes da Lapa do Mosquito, Minas Gerais. 2005. 110f. Dissertação (Mestrado) - Universidade Federal de Minas Gerais, Programa de PósGraduação em Ecologia, Conservação e Manejo da Vida Silvestre, Belo Horizonte.

RELPH, E. An inquiry into the relations between phenomenology and geography.

RODRIGUES, M.L.; FONSECA, A. A valorização do geopatrimónio no desenvolvimento sustentável de áreas rurais. In: Colóquio Ibérico de Estudos Rurais: Cultura, Inovação e 
Território, VII., 2008, Coimbra, Portugal. Anais... Coimbra: Disponível em: https://www.maxwell.vrac.puc-rio.br/22033/22033.pdf . Acesso em: 05 out. 2018. Universidade de Lisboa, 2008.

RUCHKYS, Ú. A. Patrimônio e Geoconservação no Quadrilátero Ferrífero, Minas Gerais: Potencial para a Criação de um Geoparque da UNESCO. 2007. 233f. Tese (Doutorado em Geologia) - Universidade Federal de Minas Gerais, Instituto de Geociências. Belo Horizonte.

SEAMON, D.; LUNDBERG, A. Humanistic Geography. In: RICHARDSON, D. (Ed.). International Encyclopedia of Geography: People, the Earth, Environment, and Technology. Nova Iorque: Wiley, p. 1-11. 2017.

SHARPLES C. Geoconservation in forest management - principles and procedures. Tasforests - Forestry Tasmania, Hobart, v.7, p. 37-50, dez. 1995.

SHARPLES, C. Concepts and principles of Geoconservation. Tasmania: Tasmanian Parks \& Wildlife Service website, 2002. 81p.

SILVA, C. R. et al. Começo de tudo. In: SILVA, C. R. (Ed.). Geodiversidade do Brasil: conhecer o passado, para entender o presente e prever o futuro. Rio de Janeiro: CPRM Serviço Geológico do Brasil, 2008. Cap. 1, p. 11-20.

SMITH-MEYER, S.; WIMBLEDON, W.A.P. Geoheritage in Europe and its conservation. Oslo: ProGEO, 2012. 405p.

TAVARES, A. O. et al. Community Involvement in Geoconservation: A Conceptual Approach Based on the Geoheritage of South Angola. Sustainability, n. 7, p. 4893 -4918, 2015.

TRAVASSOS, L.E.P.; AMORIM FILHO, O. B. Ibn-Battuta, geografia de viagens, carste e subterrâneos sagrados. Mercator: Fortaleza, v. 15, n.2, p. 55-75, abr.jun., 2016.

TUAN, Y. Espaço e lugar: a perspectiva da experiência. Londrina: Eduel, 2013. 248p. Tradução: Lívia de Oliveira.

UNESCO - United Nations Educational, Scientific and Cultural Organization. O Patrimônio: legado do passado ao futuro. 2018. Disponível em: http://www.unesco.org /new/pt/brasilia/culture/world-heritage/heritage-legacy-from-past-to-the-future/\#c1048735 . Acesso em 17 dez. 2018.

Vania Kele Evangelista P.

Doutora em Geografia pela PUC Minas - Tratamento da Informação Espacial e professora no Centro Federal de Educação Tecnológica de Minas Gerais - CEFET-MG. Alameda das Perdizes, 61 - Bairro Cabral Contagem/MG - CEP: 32146-054

E-mail: vaniakele@yahoo.com.br 


\section{Luiz Eduardo Panisset Travassos}

Bolsista de Produtividade em Pesquisa do CNPq (PQ-2). Doutor em Carstologia pela Universidade de Nova Gorica (Eslovênia). Professor adjunto do Departamento de Geografia da PUC Minas, onde também atua como docente permanente no Programa de Pós-Graduação em Geografia Tratamento da Informação Espacial. Av. Itaú, 505 - Jardim São José, Belo Horizonte - MG, 30535-012

E-mail: luizepanisset@gmail.com

Recebido para publicação em março de 2019 Aprovado para publicação em Junho de 2019 